\title{
Study of Yuen-Lin Liquefaction During Chi-Chi Earthquake
}

Shuhgi Chern

Professor, Department of Harbor and River Engineering, National Taiwan Ocean University, Keeling 202, Taiwan, R.O.C., sgchern@mail.ntou.edu.tw

Juei-Hsing Tsai

Graduate Student, Department of Harbor and River Engineering, National Taiwan Ocean University, Keeling 202, Taiwan, R.O.C.

Ching-Yinn Lee

Graduate Student, Department of Harbor and River Engineering, National Taiwan Ocean University, Keeling 202, Taiwan, R.O.C.

Follow this and additional works at: https://jmstt.ntou.edu.tw/journal

Part of the Civil and Environmental Engineering Commons

\section{Recommended Citation}

Chern, Shuhgi; Tsai, Juei-Hsing; and Lee, Ching-Yinn (2003) "Study of Yuen-Lin Liquefaction During Chi-Chi Earthquake," Journal of Marine Science and Technology. Vol. 11: Iss. 2, Article 6.

DOI: $10.51400 / 2709-6998.2287$

Available at: https://jmstt.ntou.edu.tw/journal/vol11/iss2/6

This Research Article is brought to you for free and open access by Journal of Marine Science and Technology. It has been accepted for inclusion in Journal of Marine Science and Technology by an authorized editor of Journal of Marine Science and Technology. 


\title{
STUDY OF YUEN-LIN LIQUEFACTION DURING CHI-CHI EARTHQUAKE
}

\author{
Shuhgi Chern*, Juei-Hsing Tsai**, and Ching-Yinn Lee**
}

\begin{abstract}
Key words: liquefaction potential index, liquefaction potential evaluation method, Chi-Chi earthquake, multiple additive decision making method (MADM).
\end{abstract}

\begin{abstract}
Extensive subsurface exploration of Yuen-Lin liquefaction area was conducted by National Science Council after Chi-Chi earthquakes. Data obtained from the subsurface exploration in Yuen-Lin area had been studied and three widely used liquefaction evaluation methods, i.e. Seed method, T-Y method and JRA method, were employed for liquefaction evaluation. The depth of the liquefied soil layer was also identified by comparison of grain size distribution curve of explored sample and field data. Iwasaki's liquefaction potential index was further used to analyze liquefaction induced risk of damage. Finally, Multiple Additive Decision Making method (MADM) was applied to determine the suitability of the three methods for liquefaction evaluation in Yuen-Lin area.

The results showed that the T-Y method is the most suitable one, followed by Seed method. The JRA method which is currently used in Taiwan's Building Code is the worst one. After 1995 Kobe earthquake, JRA method had been modified extremely, therefore, the liquefaction evaluation in Taiwan's Building Code that was developed mostly based on JRA method needs to be adjusted as well.
\end{abstract}

\section{INTRODUCTION}

On September 21 of 1999, a disastrous earthquake of magnitude 7.3 occurred at Chi-Chi in Nantou County. The strongest earthquake ever recorded in Taiwan in 20th century caused serious damages throughout the six counties of Central Taiwan. Many structures and facilities were destroyed due to soil liquefaction. Among all the reported soil liquefaction locations, Yuen-Lin and its vicinity were the most heavily damaged during the earthquake.

In order to evaluate the extend of soil liquefaction,

Paper Submitted 08/07/02, Accepted 05/30/03. Author for Correspondence: Shuhgi Chern.

*Professor, Department of Harbor and River Engineering, National Taiwan Ocean University, Keeling 202, Taiwan, R.O.C.

E-mail: sgchern@mail.ntou.edu.tw.

**Graduate Student, Department of Harbor and River Engineering, National Taiwan Ocean University, Keeling 202, Taiwan, R.O.C. to estimate the damages caused by Chi-Chi earthquake induced liquefaction and to establish the instigation policy for the earthquake hazard, National Center for Research on Earthquake Engineering (NCREE) has organized many geotechnical engineers from universities, consulting companies and government agencies to conduct field investigations and laboratory tests for the soils in the liquefaction areas (NCREE, 1999) [9]. A total of 50 standard penetration tests (SPT) and 45 cone penetration tests (CPT) were performed in Yuen-Lin area (MAA, 2000) [8].

A study of liquefaction potential and depth of liquefied soil layer was conducted based on the large number of SPT data collected from 24 of 50 subsurface explorations that liquefaction or non-liquefaction could be clearly identified. Three liquefaction evaluation methods including Seed's, T-Y's and JRA's were compared and the suitability of the three methods for liquefaction evaluation in Yuen-Lin area was determined.

\section{GEOLOGICAL CONDITION}

The town of Yuen-Lin is situated on a thick alluvial deposit of Tsosui River at the foothill of Baguasham. The soil profiles of the 24 subsurface explorations were shown in Fig. 1. There existed layers of very loose sandy soils with SPT-N values as low as 2 . The ground

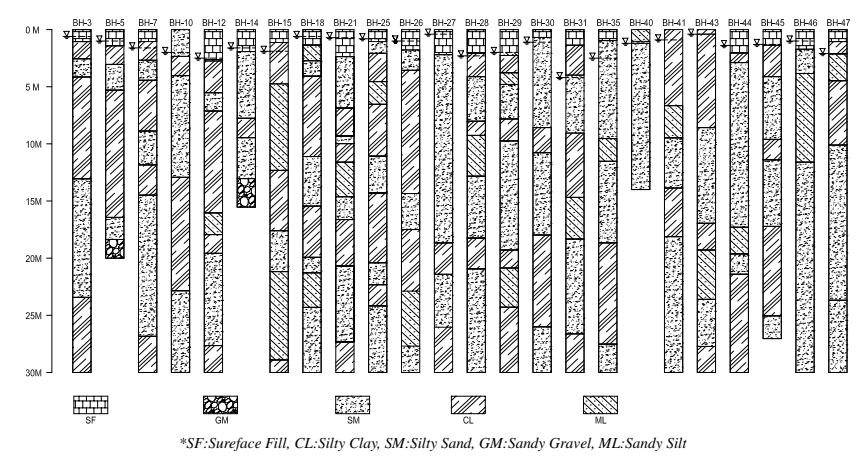

Fig. 1. Profiles of subsurface explorations (NCREE, 1999) 
water level was generally high at about $0.4 \mathrm{~m}$ to $4.0 \mathrm{~m}$ below ground surface. Liquefaction occurred in layers of sandy soil with low SPT-N values, usually less than 10. Sand boiling was not usually observed in the areas with thick clay layers on top of the liquefiable sandy layers (Lin et al., 2000) [6].

Grain size distributions of ejected and explored samples were shown in Fig. 2 (NCREE, 2000). From Fig. 2, it could be seen that most of the gathered specimens contained high percentages of non-plastic fines, and all the grain size distribution curves were almost all fell inside the boundaries for potentially and most liquefiable soils $\left(D_{50}=0.08 \sim 0.2 \mathrm{~mm}\right)$. Comparison of the grain size distribution of the ejected samples and explored samples taken at the same location could provide some reliable clues to identify the soil layer where liquefaction occurred during the earthquake (Lin et al., 2000) [6]. For the sites lacked of ejected soil sample, the probably liquefied depths could be determined based on the soil profile, the ground water level, the SPT-N value, and the soil type.

\section{LIQUEFACTION POTENTIAL EVALUATION METHODS}

There were many methods to assess the liquefaction potential, however, only the Seed's method, the T$\mathrm{Y}$ method, and the JRA method were employed in this study, and the outcomes were presented as liquefaction potential index proposed by Iwasake.

Seed's method was proposed by Seed et al. (1971, 1985) $[10,12]$ and was modified by NCEER (1997). The corrected SPT resistance of in-site soil stratum was compared with earthquake-induced cyclic shear stress.

Tokimatsu and Yoshimi's method (T-Y method, 1983)was suggested by Tokimatsu and Yoshimi (1983)

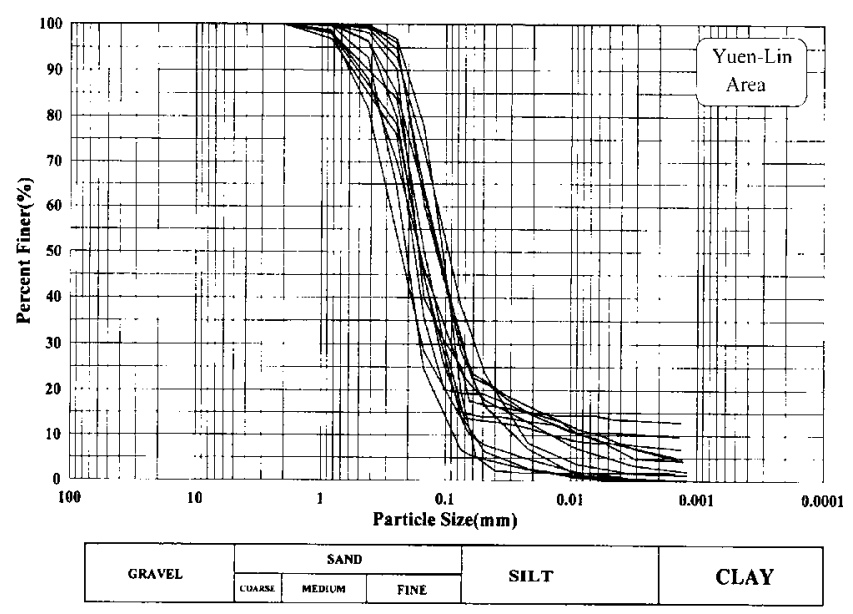

Fig. 2. Grain size distribution curves of liquefied soils (NCREE, 1999)
[13]. Basically, the method combined the data from collecting liquefaction and non-liquefaction cases happened in Japan and other countries, and from performing cyclic triaxial tests using high quality frozen soil specimens. SPT-N values and fines content are the major parameters considered.

Though the 1990 Japan Road Association's method (JRA method, 1990) [4] had been modified by Japan Road Association (1996) after the 1995 HyogokenNanbu earthquake occurred in Japan, JRA method is still used in Taiwan's Building Code. This method was originally developed by Iwasaki et al. (1978, 1982) [2, 3 ], based on collected liquefaction and non-liquefaction cases of six earthquakes occurred in Japan, and cyclic triaxial test results of high quality undisturbed soil specimens. Compared with Seed's method, JRA method considered mean grain size $D_{50}$ as the parameter of liquefaction resistance in addition.

The ability to resist liquefaction at a given depth of soil layer can be evaluated by the safety factor $F_{L}$, and the liquefaction induced structural damage is considered being affected by the severity of liquefaction degree.

In view of this fact, Iwasaki et al. (1982) [2] proposed the liquefaction potential index $P_{L}$ to estimate the severity of liquefaction degree at a given site, as defined by eq. (1):

$$
P_{L}=\int_{0}^{20} F(z) w(z) d z \quad(z=0 \sim 20 \mathrm{~m})
$$

where, $F(z)=0 \sim 1$, coefficient of liquefaction resistance; $F(z)=1-F_{L}$

$w(z)=10-0.5 z$, weighting coefficient of depth $z$.

Based on cases studied in Japan, Iwasaki et al. (1982) [2] proposed the following judgment indices:
$P_{L}=0$ :
Liquefaction risk is very low
$0<P_{L} \leq 5$ : Liquefaction risk is low
$5<P_{L} \leq 15$ : Liquefaction risk is high
$P_{L}>15: \quad$ Liquefaction risk is very high

\section{LIQUEFACTION EVALUATION DURING CHI-CHI EARTHQUAKE}

The results of liquefaction potential analyses using the methods described above in terms of $P_{L}$ were shown in Table 1 and Fig. 3. It was found that liquefaction occurred in sandy layers at depth between $4 \mathrm{~m}$ to 10 $\mathrm{m}$. The results calculated from the three methods showed that Seed's method had the lowest safety factor and highest liquefaction risk, whereas T-Y and JRA methods had higher safety factors and lower liquefaction risk, as shown in Table 1 and Fig. 3.

Comparison of the analyzed results and field data of boreholes $\mathrm{BH}-3$ and $\mathrm{BH}-5$, the liquefaction risks 
Table 1. Estimated liquefaction potential indexes

\begin{tabular}{ccccc}
\hline & & & \multicolumn{2}{c}{ Liquefaction Potential Index } \\
\cline { 3 - 5 } Borehole No. & If Liquefied & Seed (NCEER,1997) & $\begin{array}{c}\text { Tokimatsu \& Yoshimi } \\
(1983)\end{array}$ & JRA (1990) \\
& & & 9.29 & 4.88 \\
BH-3 & Y & 23.45 & 5.46 & 0.00 \\
BH-5 & Y & 14.82 & 6.46 & 1.23 \\
BH-7 & N & 19.89 & 3.16 & 10.68 \\
BH-10 & N & 10.78 & 1.81 & 0.61 \\
BH-12 & N & 8.39 & 2.62 & 6.12 \\
BH-14 & N & 6.34 & 2.59 & 0.07 \\
BH-15 & N & 7.15 & 0.29 & 4.68 \\
BH-17 & N & 9.09 & 9.70 & 1.02 \\
BH-18 & Y & 20.48 & 5.21 & 5.32 \\
BH-21 & Y & 13.25 & 8.48 & 1.06 \\
BH-25 & Y & 14.85 & 4.25 & 3.06 \\
BH-26 & Y & 9.42 & 17.72 & 0.71 \\
BH-27 & N & 24.98 & 3.68 & 4.33 \\
BH-28 & Y & 15.16 & 1.27 & 6.76 \\
BH-29 & Y & 10.98 & 5.60 & 1.35 \\
BH-30 & Y & 9.83 & 0.60 & 0.00 \\
BH-31 & N & 9.71 & 0.43 & 1.91 \\
BH-35 & Y & 3.91 & 2.13 & 3.47 \\
BH-40 & Y & 2.22 & 1.73 & 4.01 \\
BH-41 & N & 13.21 & 12.79 & 10.73 \\
BH-43 & Y & 26.55 & 15.27 & 1.86 \\
BH-44 & Y & 19.00 & 4.46 & 1.09 \\
BH-45 & Y & 12.51 & 7.08 & 0.15 \\
BH-46 & Y & 22.12 & 0.05 & \\
BH-47 & Y & 9.43 & & \\
\hline
\end{tabular}

*BH-17 ground water level was unknown

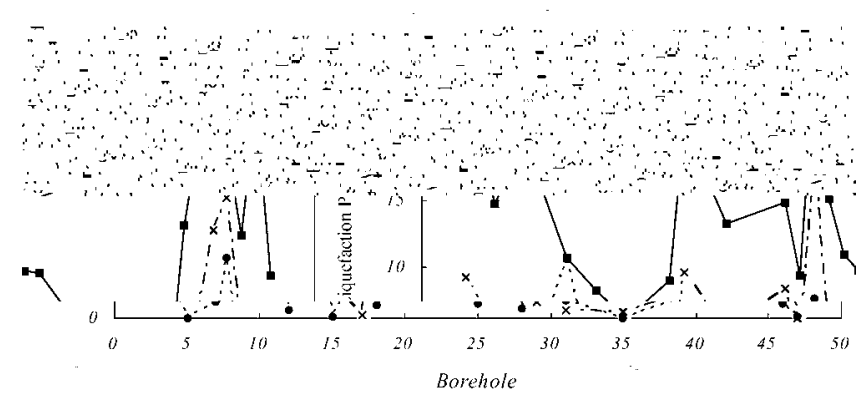

Fig. 3. Borehole's liquefaction potential index.

were high to very high estimated by modified Seed's and T-Y's methods, the results were fairly consistent with the reported subsidence and sand boiling. However, $P_{L}$ values obtained by JRA method were 4.88 and 0 for
BH-3 and BH-5, respectively, i.e., liquefaction risks were low and very low. The results were not consistent with field observations. Moreover, the results analyzed by modified Seed's method showed that the liquefaction risks at sites of boreholes $\mathrm{BH}-21, \mathrm{BH}-28$ and $\mathrm{BH}-$ 29 were high, were also consistent with field observations, whereas the liquefaction risks obtained by JRA and T\&Y's methods were low.

Based on the analyses performed in this study, it was found that at locations where soil contained high percentage of fines content, the soil resistance calculated in JRA's method was higher than Seed's and T-Y's methods. For examples, there were subsidence and sand boiling at sites of boreholes $\mathrm{BH}-5, \mathrm{BH}-35$ and $\mathrm{BH}-47$, while $P_{L}$ obtained by JRA's method were only $0 \sim 0.15$, i.e., liquefaction risks were very low to low.

Comparison of results analyzed by the three methods at sites of boreholes BH-7, BH-10, BH-12, BH-14, $\mathrm{BH}-15, \mathrm{BH}-31$ and $\mathrm{BH}-41$ where no subsidence or sand boiling occurred during Chi-Chi earthquake showed 
that except for borehole BH-7, T-Y's method had $P_{L}$ values between 0.05 and 3.16, i.e., the liquefaction risks were low; JRA's method led to almost similar results except for boreholes BH-10 and BH-14; whereas Seed's method had $P_{L}$ values high between 6 and 20, i.e., liquefaction risks were high to very high. Obviously, Seed's method did not evaluate liquefaction potential well for non-liquefied sites. The subsurface exploration showed that all boreholes mentioned above had low SPT-N values and very high fines content. The Seed's method produced high liquefaction potential index at these boreholes because the resistance of soil against liquefaction would not be increased with fines content more than 35\%, and resistance was under-estimated when SPT-N value was low, resulting in over-estimation of liquefaction potential index by using Seed's method.

The ground water level in borehole $\mathrm{BH}-27$ is at $0.4 \mathrm{~m}$ below ground surface and is the highest one among all boreholes explored. Comparison of liquefaction risks evaluated by the three methods in this borehole, the Seed's method yielded very high liquefaction potential index $\left(P_{L}=24.98\right)$; the T-Y method also gave similar result $\left(P_{L}=17.72\right)$; the JRA method yielded the lowest liquefaction potential index $\left(P_{L}=7.8\right)$, however, the liquefaction risk obtained by JRA method is still high. Examined BH-27 site, no subsidence or sand boiling was observed during earthquake, i.e., the site was not liquefied. The reason of discrepancy was due to high ground water level at this site, resulting in very low effective stress, hence low soil resistance against liquefaction.

Compared grain size distribution curves of the samples taken at locations where liquefaction had occurred with gradation of soil having liquefaction possibility proposed by Japanese Society of Civil Engineering (JSCE, 1977) [5], might provide different point of view for liquefaction evaluation.

The grain size distribution curves of boreholes BH-28, BH-41 and BH-44, were shown in Fig. 4. In Fig. 4 also showed JSCE proposed gradation curve of soil with possibility and high possibility of liquefaction.

It was found that about 50 90\% of the gradation curves situated in the possible and highly possible liquefaction zones and the fines content of these samples ranged from $10 \%$ to $70 \%$. These sample soils had no plasticity, and were classified as SM or ML in the Unified Soil Classification System (USCS). Because there were many soils with high fines content had been liquefied during Chi-Chi earthquake, the influence of fines content on liquefaction potential evaluation needed further studying.

In Seed's method (1983) [11], mean grain size $D_{50}$ was firstly considered as the influence factor on liquefaction, then the fines content was considered instead (1985). However, because the cyclic resistance of soil would not be increased with fines content more than $35 \%$ using Seed's method, the resistance of soil with fines content more than $35 \%$ would be under-estimated, resulting in over-estimation of liquefaction potential index.

\section{SUITABILITY EVALUATION}

From above discussions, the methods used to evaluate liquefaction potential did not agree very well at some sites with the situations happened during the earthquake. Therefore, their suitability needed to be examined further. In this study, multiple attribute decision making (MADM) together with Simple Additive Weighting method (SAW) were used to quantify evaluation results and to examine the suitability of the methods.

Simple additive weighting method (SAW) is probably the best known and very widely used method of MADM. The method is well summarized by MacCrimmon (MacCrimmon, 1968) [7]. To each of the attributes in SAW, the Decision Making (DM) assigns importance weights which become the coefficients of the variables. To reflect the DM's marginal worth assessments within attributes, the DM also makes a numerical scaling of intra-attribute values. The DM can then obtain a total scores for each alternative simply by multiplying the scale rating for each attribute value by the importance weight assigned to the attribute and then summing these products over all attributes. After the total scores are computed for each alternative, the alternative with the highest score (the highest weighted average) is the one prescribed to the DM (Hwang and Yoon, 1981) [1].

Mathematically, simple additive weighting method can be stated as follows: Suppose the DM assigns a set of importance weights to the attributes, $w=\left[w_{1}, w_{2}, w_{3}\right.$, $\left.\ldots, w_{n}\right]$, then the most preferred alternative is selected.

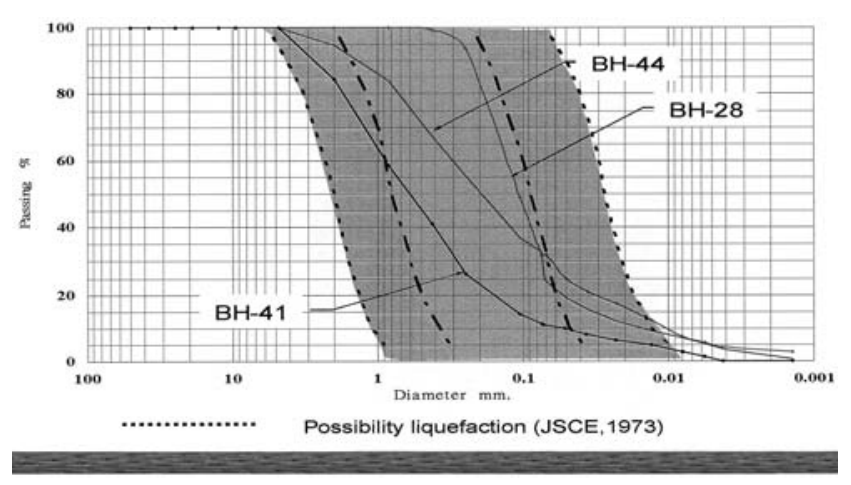

Fig. 4. Grain size distribution curves of BH-28, BH-41, BH-44. 
Table 2. Transformed Iwasaki's index into evaluation performance value

\begin{tabular}{ccc}
\hline Site Liquefied or not & $\begin{array}{c}\text { Iwasaki Liquefaction } \\
\text { Potential Index }\end{array}$ & $\begin{array}{c}\text { Evaluation } \\
\text { performance value }\end{array}$ \\
\hline \multirow{3}{*}{ Site Liquefied } & $0<P_{L}<1$ & 1 \\
& $1<P_{L}<5$ & 3 \\
& $5<P_{L}<15$ & 5 \\
Site not Liquefied & $15<P_{L}$ & 7 \\
\hline & $0<P_{L}<1$ & 7 \\
& $1<P_{L}<5$ & 5 \\
& $5<P_{L}<15$ & 3 \\
& $15<P_{L}$ & 1 \\
\hline
\end{tabular}

Usually the weights are normalized so that $\sum_{j=1}^{n} w_{j}=1$.

Simple additive weighting method (SAW) uses all $n$ attribute values of an alternative and uses the regular arithmetical operations of multiplication and addition; therefore, the attribute values must be both numerical and comparable. Further, it is also necessary to find a reasonable basis on which to form the weights reflecting the importance of each of the attributes (Hwang et al., 1981). The steps for applying the MADM to determine the suitability of the three methods for liquefaction evaluation in Yuen-Lin area were described as follows:

\section{Criteria}

Based on Iwasaki's liquefaction potential index $P_{L}$ (Table 1) and site observations during earthquake, $P_{L}$ values were transformed into four categories:

(1) 7 points: $P_{L}$ value was consistent very well with site observation, i.e. liquefied with $P_{L}>15$ or not liquefied with $P_{L}=0$

(2) 5 points: $P_{L}$ value was consistent agree well with site observation, i.e. liquefied with $P_{L}=5 \sim 15$ or not liquefied with $P_{L}=0 \sim 1$

(3) 3 points: $P_{L}$ value was not consistent with site observation, i.e. liquefied with $P_{L}=0 \sim 5$ or not liquefied with $P_{L}=5 \sim 15$

(4) 1 points: $P_{L}$ value was not consistent at all with site observation, i.e. liquefied with $P_{L}=0 \sim 1$ or not liquefied with $P_{L}>15$

The evaluation criteria as described above were shown in Table 2. Based on these criteria the site observations (Yes or No) and $P_{L}$ values listed in Table 1 could then be transformed into evaluation performance values.

\section{Normalized performance value}

The evaluation performance values estimated in step 1 were normalized by following equation:

$$
W_{j}=\frac{P_{j}}{\operatorname{MaxP}_{j}}
$$

where $p_{j}=$ evaluation performance value as estimated from step 1

The normalized evaluation performance values were listed in Table 3. If the performance value $w_{j}$ listed in Table 3 was high and close to 1 , indicated that the evaluation result was agreeable with site observation. On the other hand, if the performance value was low and close to zero, indicated that the evaluation result did not agree with site observation.

\section{Mean of performance value}

Assume $P_{L}$ value calculated by Iwasaki's liquefaction potential evaluation method at any borehole was not affected by the results obtained at the other boreholes, i.e., $P_{L}$ value obtained at every borehole had the same weighted value (all $w_{j}$ had the same value), the mean of performance values could be determined as:

$$
s=\frac{\sum_{j=1}^{n} w_{j}}{n}
$$

Table 3 also listed the mean performance values determined by the three methods.

\section{Sequence of decision-making}

Based on mean of performance values determined from step 3, the sequence of deciding best evaluation method could be determined. For all mean values listed in Table 3, it was found that T-Y's method had the highest score, followed by Seed's method and then JRA's method, i.e., T-Y's method is the most suitable one in the study for liquefaction potential evaluation in Yuen-Lin area, JRA's method is the worst one.

The normalized performance values listed on Table 3 that were evaluated by the three methods showed that 
Table 3. Normalized performance values of SPT-N liquefaction potential indexes

\begin{tabular}{|c|c|c|c|c|}
\hline \multirow[b]{2}{*}{ Borehole No. } & \multirow[b]{2}{*}{ If Liquefied } & \multicolumn{3}{|c|}{ Normalized performance values of Liquefaction Potential Indexes } \\
\hline & & $\begin{array}{c}\text { Seed } \\
(\text { NCEER, 1997) }\end{array}$ & $\begin{array}{c}\text { Tokimatsu \& Yoshimi } \\
(1983)\end{array}$ & JRA (1990) \\
\hline BH-3 & $\mathrm{Y}$ & 1.000 & 0.714 & 0.429 \\
\hline BH-5 & $\mathrm{Y}$ & 0.714 & 0.714 & 0.143 \\
\hline $\mathrm{BH}-7$ & $\mathrm{~N}$ & 0.143 & 0.429 & 0.714 \\
\hline BH-10 & $\mathrm{N}$ & 0.143 & 0.714 & 0.429 \\
\hline BH-12 & $\mathrm{N}$ & 0.143 & 0.714 & 0.714 \\
\hline BH-14 & $\mathrm{N}$ & 0.143 & 0.714 & 0.429 \\
\hline BH-15 & $\mathrm{N}$ & 0.143 & 0.714 & 1.000 \\
\hline BH-18 & Y & 1.000 & 0.714 & 0.429 \\
\hline BH-21 & $\mathrm{Y}$ & 0.714 & 0.714 & 0.714 \\
\hline BH-25 & Y & 0.714 & 0.714 & 0.429 \\
\hline BH-26 & $\mathrm{Y}$ & 0.714 & 0.429 & 0.429 \\
\hline ВН-27 & $\mathrm{N}$ & 0.143 & 0.143 & 0.429 \\
\hline BH-28 & $\mathrm{Y}$ & 1.000 & 0.429 & 0.429 \\
\hline ВН-29 & $\mathrm{Y}$ & 0.714 & 0.429 & 0.429 \\
\hline ВH-30 & $\mathrm{Y}$ & 0.714 & 0.714 & 0.714 \\
\hline ВH-31 & $\mathrm{N}$ & 0.429 & 1.000 & 0.714 \\
\hline ВН-35 & $\mathrm{Y}$ & 0.429 & 0.429 & 0.143 \\
\hline BH-40 & $\mathrm{Y}$ & 0.429 & 0.429 & 0.429 \\
\hline ВH-41 & $\mathrm{N}$ & 0.429 & 0.714 & 0.714 \\
\hline BH-43 & $\mathrm{Y}$ & 1.000 & 0.714 & 0.429 \\
\hline ВH-44 & Y & 1.000 & 1.000 & 0.714 \\
\hline BH-45 & Y & 0.714 & 0.429 & 0.429 \\
\hline BH-46 & $\mathrm{Y}$ & 1.000 & 0.714 & 0.429 \\
\hline BH-47 & $\mathrm{Y}$ & 0.714 & 0.143 & 0.429 \\
\hline \multicolumn{2}{|c|}{ Average of performance value } & 0.595 & 0.607 & 0.512 \\
\hline \multicolumn{2}{|c|}{ Suitability evaluation sequence 2} & 1 & 3 & \\
\hline
\end{tabular}

although for boreholes (BH-3, BH-5, BH-18, BH-21, ВН-25, ВН-26, ВН-28, ВН-29, ВН-30, ВН-35, ВН-40, $\mathrm{BH}-43, \mathrm{BH}-44, \mathrm{BH}-45, \mathrm{BH}-46$ and $\mathrm{BH}-47$ ) where liquefaction had occurred, Seed's method had the highest normalized performance values, howere, for boreholes (BH-7, BH-10, BH-12, BH-14, BH-15, BH-27, BH-31 and $\mathrm{BH}-41$ ) where liquefaction did not occurred, Seed's method had the lowest normalized performance values. Consequently, Seed's method was second suitable one on average. On the other hand, though T \& Y's method had the second highest performance values for boreholes that did liquefy, it had almost the highest performance values as JRA's method, therefore, T \& Y's method was listed the most suitable one on average.

Obviously Seed's method did not evaluate liquefaction well for non-liquefied sites. The Seed's method produced high liquefaction potential index and low performance value at non-liquefied sites because the resistance of soil against liquefaction would not be increased with fines content more than $35 \%$, and resistance was under-estimated when SPT-N value was low, resulting in over-estimation of liquefaction potential index $P_{L}$ and low performance value by using Seed's method. If the resistance of soil against liquefaction could be increased with fines content more than $35 \%$, the performance value of liquefaction potential evaluated by Seed's method might be improved, and the Seed's method would be considered as the most suitable one for evaluation of liquefaction potential.

\section{CONCLUSION}

Based on the above analyses and discussion, the following conclusions are made:

1. The SPT-N simplified methods used in this study are based on a large amount of field performance data together with laboratory test results, and are widely used in the world. However, they are not consistent with all the reported field observations in Yuen-Lin area, i.e., they need to be modified when used locally.

2. Variations existed in studying of influence of fines content on resistance of soil against liquefaction. Seed's method is too conservative for soils with high percentage of fines content, if it could be modified to 
increase soil resistance against liquefaction with fines content being more than $35 \%$, the suitability could be improved.

3. The results of suitability analyses show that T-Y method is the most suitable one, followed by Seed method. The JRA method which is currently used in Taiwan's Building Code is the worst one. JRA method had been modified as NJRA method in Japan, the liquefaction evaluation method used in local Building Code needs to be corrected as well based on recent research results

\section{REFERENCES}

1. Hawng, C.L. and Yoon, K., Multiple Attribute Decision Making-Methods and Applications, Springer-Verlag, New York, pp. 99-103 (1981).

2. Iwasaki, T., Arakawa, T., and Tokida, K.,"Simplified Procedures for Assessing Soil Liquefaction During Earthquakes ," Soil Dynamics and Earthquake Engineering Conference Southampton, pp. $925-939$ (1982).

3. Iwasaki, T., Tatsuoka, F., and Yasuda, S., "A practical Method for Assessing Soil Liquefaction Potential Based on Case Studies at Various Sites in Japan," Proceedings of the $2^{\text {nd }}$ International Conference Microzonation Safer Construction Research Application, Vol. 2, pp. 885-896 (1978).

4. Japan Road Association (JRA), Specifications for Highway Bridges, Vol. V: Earthquake Resistant Design (in Japan) (1990).

5. JSCE, Earthquake Resistant Design for Civil Engineering Structure, Earth Structure and Foundation in Japan,
Japan Society of Civil Engineering (1977).

6. Lin, M.L.,Ueng, T.S., Chen, M.H., and Huang, S.C., A Preliminary Study on Evaluation of Liquefaction Potential of Yuen-Lin Area, Proceedings of International Workshop on Annual Commemoration of Chi-Chi Earthqake, Vol. III-Geot. Aspect, NCREE, Taipei, pp. 74-82 (2000).

7. MacCrimmon, K.R., Decision Making Among MultipleAttribute Alternatives: A Survey and Consolidated Approach, RAND Memorandum, RM-4823-ARPA (1968).

8. Moh and Association (MAA), Soil Liquefaction and Mitigation Study, phase I (Yuen-Lin, Da-Chun, and Sheh-Ton), Final Report to NSC (2000).

9. NCREE, Reconnaissance Report of the Geotechnical Hazard caused by Chi-Chi Earthquake, National Center for Research on Earthquake Engineering, Taipei, Taiwan (1999).

10. Seed, H.B. and Idriss, I.M.," Simplified Procedure for Evaluating Soil Liquefaction Potential," J. Soil Mechanics Found. Divi., ASCE, Vol. 97, No. SM9, pp. 12491273 (1971).

11. Seed, H.B., Tokimatsu, K., Harder, L.F., "Influence of SPT Procedure In Soil Liquefaction Resistance Evaluations," J. Geotech. Engin., ASCE, Vol. 109, No. 3, pp. 458-482 (1983).

12. Seed, H.B., Tokimatsu, K., Harder, L.F., and Chung, R. M.," Influence of SPT Procedure on Soil Liquefaction Resistance Evaluations, " J. Geotech. Engin., ASCE, Vol. 111, No. 12, pp. 1425-1445 (1985).

13. Tokimatsu, K. and Yoshimi, Y.," Empirical Correlation of Soil Liquefaction Based on SPT-N Value and Fines Contents," Soil Found., Vol. 23, No. 4, pp. 56-74 (1983). 